•生物编目・国家重点保护野生植物专题

\title{
中国裸子植物红色名录评估(2021版)
}

杨永(

南京林业大学生物与环境学院，南方现代林业协同创新中心，南京 210037

摘要: 定期开展物种红色名录评估, 了解植物濒危状态、致危因素变化, 对于物种保育有重要意义。本文报道了国产裸子植 物的最新评估结果, 并与 2013 版红色名录进行了比较。本次评估了国产裸子植物 274 个种和种下分类群(隶属于 8 科 37 属)。与 2013 版红色名录相比, 本次评估减少了 2 科, 增加了 3 属和 40 个种和种下分类群。分类群变化是由于上次评估遗漏属种、新类 群、新分布记录以及分类群名称和等级变化所致。本次评估有139个种和种下分类群被列入受威胁等级(包括极危、濒危和易 危), 占总评估种类的 $50.7 \%$, 与 2013 版的 $51.0 \%$ 相比, 受威胁程度基本不变。物种自身进化属性、资源过度利用、生境丧失和 全球变暖是国产裸子植物的主要致危因素。此外, 还有 27 种列为数据缺乏(DD), 占总种数的 $9.9 \%$, 较 2013 版略有增加, 表明 我国裸子植物需开展针对性野外调查和相关研究, 以摸清物种的野外生存现状, 为深入认识我国裸子植物濒危程度奠定数据 基础。新的红色名录评估对濒危物种保育实践也有重要意义。

关键词: 中国; 裸子植物; 红色名录; 分类; 濒危物种; 保育

杨永 (2021) 中国裸子植物红色名录评估(2021版). 生物多样性, 29, 1599-1606. doi: 10.17520/biods.2021342.

Yang Y (2021) An updated red list assessment of gymnosperms from China (Version 2021). Biodiversity Science, 29, 1599-1606. doi: 10.17520/biods.2021342.

\section{An updated red list assessment of gymnosperms from China (Version 2021)}

\section{Yong Yang ${ }^{(\mathbb{D} *}$}

Co-Innovation Center for Sustainable Forestry in Southern China, College of Biology and the Environment, Nanjing Forestry University, Nanjing 210037

\section{ABSTRACT}

Aims: It is important to conduct periodical red list assessments, understand the threatened status and threats, for effective species conservation. Here we report a new red list assessment of gymnosperm species native to China with a comparison between this new assessment and the earlier assessment released in 2013.

Methods: We collected species data from published references and databases and adopted the IUCN Red List Categories and Criteria ver. 3.1 for the red list assessment.

Results: This new red list assessment of gymnosperms includes 274 species and infraspecies, belonging to 37 genera and 8 families, all of which are native to China. Compared with the red list version released in 2013, 2 families were reduced in priority, while 3 genera and 40 species and infraspecies increased in priority during this study. These changes are caused by updating recent taxonomic novelties and adding a few taxa missing in the previous assessment. Among the 274 assessed specific and infraspecific taxa, 139 were listed as threatened (including Critically Endangered (CR), Endangered (EN), and Vulnerable (VU)). Of the total assessed species, up to $50.7 \%$ are listed as threatened, which is similar to the proportion of the previous assessment. In addition, there are 27 species and infraspecies listed as Data Deficient (DD), approximately $9.9 \%$ of the total assessed species.

Conclusions: Threats to Chinese gymnosperm species include internal attributes of relic and endemic species, over-exploitation, habitat loss, and global warming. The high ratio of Data Deficient (DD) species suggests that it is necessary to conduct targeted field investigations to better understand the living status and threats of gymnosperms in China in order to lay a solid foundation for the next red list assessment. The new assessment will be helpful to guide conservation practices of Chinese gymnosperms. 
Key words. China; gymnosperms; red list; taxonomy; threatened species; conservation

裸子植物起源于 3.85 亿年前的中泥盆世, 繁盛 于晚古生代和早中生代, 在白严纪随着被子植物的 兴起后逐渐衰落, 现存仅 4 条传代线, 即苏铁类、银 杏类、松柏类和买麻藤类，包含 8 目 12 科 85 属 1,118 种(杨永等, 2017)。尽管裸子植物及其主要传代线起 源古老, 但现存种类很多是在中新世以来分化形成, 北半球的物种更新速率较南半球更快(Nagalingum et al, 2011; Leslie et al, 2012)。裸子植物在陆地生态 系统中起着举足轻重的作用, 全球森林面积的 $39 \%$ 以上由松柏类构成; 木材材质优良, 有非常广泛的 应用(杨永等, 2017)。它们还是重要的食用和药用植 物, 松树(Pinus spp.)的松子和棑树(Torreya grandis) 的种子香榧可以食用, 苏铁类、银杏 (Ginkgo biloba)、雪松(Cedrus deodara)、水杉(Metasequoia glyptostroboides)、金钱松 (Pseudolarix amabilis)、落 叶松(Larix spp.)、白皮松(Pinus bungeana)等是常见 的园林树种, 银杏、麻黄(Ephedra spp.)、红豆杉 (Taxus spp.) 是重要的药用植物。因此, 对裸子植物 开展分类和保护研究有重要的理论意义和实际应 用价值。

红色名录评估(red list assessments)有助于认识 物种的濒危现状和受威胁因素, 从而制订有针对性 的保育策略。红色名录评估是应用世界自然保护联 盟(International Union for Conservation of Nature, IUCN) 的红色名录等级和标准 (IUCN Red List Categories and Criteria v. 3.1), 依据观测或推测的数 据分析物种种群动态( $\mathrm{A}$ 标准)、分布区面积(B和 $\mathrm{D}$ 标 准)、成熟植株数量(C和D标准)和居群活力等, 以此 评定物种的灭绝风险(IUCN, 2012)。

定期开展物种红色名录评估有助于了解物种 野外生存现状及致危因子的变化情况, 从而有助于 及时修正保育策略, 有效保护濒危物种。中国高等 植物红色名录首次全面评估完成于 2010 年, 于 2013 年由环境保护部与中国科学院联合发布, 即《中国 生物多样性红色名录——高等植物卷》 (https://ww w.mee.gov.cn/gkml/hbb/bgg/201309/t20130912_2600 61.htm)。第一次全面评估距今已经10年, 近年来我 国裸子植物分类学研究和野外生存状态数据已经 发生了很多变化。本文基于我国裸子植物的新数据 更新了我国裸子植物的红色名录, 比较了本次评估
结果和2013版红色名录的差异, 探讨了存在的问题 及解决方案。

\section{材料与方法}

从中国知网、 Web of Science、中国数字植物标 本馆(Chinese Virtual Herbarium, CVH, https://www. cvh.ac.cn/) 和中国自然标本馆 (Chinese Field Herbarium, CFH, http://www.cfh.ac.cn/)等文献和数 据平台收集2010年1月至2021年4月之间的裸子植 物分类学、谱系地理学、种群调查等方面的相关资 料, 整合完善中国裸子植物的物种编目数据库, 形 成红色名录评估的物种名录数据库。使用IUCN Red List Categories and Criteria v. 3.1 (IUCN, 2012)进行 评估, 包括9个等级, 即灭绝(Extinct, EX)、野外灭绝 (Extinct in the Wild, EW)、板危 (Critically Endangered, CR)、濒危(Endangered, EN)、易危 (Vulnerable, VU)、 近危(Near Threatened, NT)、无危(Least Concern, LC)、数据缺乏(Data Deficient, DD) 和未评估(Not Evaluated, NE)。初评结果提交红色名录专家组进行 审核, 依据专家反馈建议对评估结果进行修订, 最 终完成我国裸子植物的红色名录评估。

\section{结果和讨论}

\section{1 评估类群变化}

本次评估结果见附录 1 和表 1 。评估的 274 个分 类群隶属于 8 个科: 苏铁科 23 种, 银杏科 1 种, 松科 124 种, 罗汉松科19种, 柏科55种, 红豆杉科 27 种, 麻黄科18种, 买麻藤科7种。2013版的名录包括249 个种和种下分类群, 隶属于10科34属。与2013版相 比, 科级水平上三尖杉科并入了红豆杉科, 杉科并 入了柏科。根据克氏系统(Christenhusz et al, 2011), 全世界裸子植物共 12 科, 我国产 8 科, 而泽米铁科、 南洋杉科、金松科和百岁兰科等4科我国不产。

评估的 274 个种和种下分类群隶属于 37 属, 其 中超过 10 个分类群的 8 个属为: 松属(Pinus, 36)、刺 柏属(Juniperus, 30)、冷杉属(Abies, 27)、云杉属 (Picea，26)、苏铁属(Cycas，23)、麻黄属(Ephedra, 18)、罗汉松属(Podocarpus, 14)和落叶松属(Larix, 12)。属级水平上增加了3个属, 即雪松属(Cedrus)、 长苞铁杉属(Nothotsuga)和金柏属(Xanthocyparis)。 
表12021版和2013版中国裸子植物红色名录评估结果比较

Table 1 A comparison of red list assessment of Chinese gymnosperms between version 2021 and 2013

\begin{tabular}{|c|c|c|c|c|c|c|c|c|c|c|}
\hline \multirow[t]{2}{*}{ 科 Family } & \multicolumn{5}{|c|}{ 2021版 Version 2021} & \multicolumn{5}{|c|}{ 2013版 Version 2013} \\
\hline & $\begin{array}{l}\text { 评估种数 } \\
\text { Assessed } \\
\text { species }\end{array}$ & $\begin{array}{l}\text { 受威胁物种 } \\
\text { Threatened } \\
\text { species } \\
\text { (\%) }\end{array}$ & $\begin{array}{l}\text { 无危 } \\
\text { Least } \\
\text { Concern } \\
(\%)\end{array}$ & $\begin{array}{l}\text { 近危 } \\
\text { Near } \\
\text { Threatened } \\
(5 \%)\end{array}$ & $\begin{array}{l}\text { 数据缺乏 } \\
\text { Data } \\
\text { Deficient } \\
\text { (\%) }\end{array}$ & $\begin{array}{l}\text { 评估种数 } \\
\text { Assessed } \\
\text { species }\end{array}$ & $\begin{array}{l}\text { 受威胁物种 } \\
\text { 1 Threatened } \\
\text { species } \\
\text { (\%) }\end{array}$ & $\begin{array}{l}\text { 无危 } \\
\text { Least } \\
\text { Concern } \\
(\%)\end{array}$ & $\begin{array}{l}\text { 近危 } \\
\text { Near } \\
\text { Threatened } \\
(5 \%)\end{array}$ & $\begin{array}{l}\text { 数据缺乏 } \\
\text { Data } \\
\text { Deficient } \\
\text { (\%) }\end{array}$ \\
\hline 苏铁科 Cycadaceae & 23 & $22(95.7 \%)$ & 0 & 0 & 1 & 22 & $22(100 \%)$ & 0 & 0 & 0 \\
\hline 银杏科 Ginkgoaceae & 1 & $1(100 \%)$ & 0 & 0 & 0 & 1 & $1(100 \%)$ & 0 & 0 & 0 \\
\hline 麻黄科 Ephedraceae & 18 & $2(11.1 \%)$ & $11(61.1 \%)$ & $3(16.7 \%)$ & $2(11.1 \%)$ & 15 & $2(13.3 \%)$ & $11(73.8 \%)$ & $2(13.3 \%)$ & 0 \\
\hline 买麻藤科 Gnetaceae & 7 & 0 & $6(85.7 \%)$ & 0 & $1(14.3 \%)$ & 9 & $1(11.1 \%)$ & $7(77.8 \%)$ & 0 & $1(11.1 \%)$ \\
\hline 松科 Pinaceae & 124 & $55(44.4 \%)$ & $52(41.9 \%)$ & $6(4.8 \%)$ & $11(8.9 \%)$ & 121 & $52(43 \%)$ & $52(43.0 \%)$ & $6(5.0 \%)$ & $11(9.1 \%)$ \\
\hline 罗汉松科 Podocarpaceae & e19 & $13(68.4 \%)$ & $1(5.3 \%)$ & $1(5.3 \%)$ & $4(21.1 \%)$ & 13 & $11(84.6 \%)$ & $2(15.4 \%)$ & 0 & 0 \\
\hline 柏科 Cupressaceae & 55 & $24(43.6 \%)$ & 19 (34.5\%) & $4(7.3 \%)$ & $8(14.5 \%)$ & 45 & $20(44.4 \%)$ & $17(37.8 \%)$ & $3(6.7 \%)$ & $5(11.1 \%)$ \\
\hline 红豆杉科 Taxaceae & 27 & 22 (81.5\%) & 4 (14.8\%) & $1(3.7 \%)$ & 0 & 23 & 18 (78.3\%) & $4(17.4 \%)$ & 1 (4.3\%) & 0 \\
\hline 合计 Total & 274 & 139 (50.7\%) & 93 (33.9\%) & 15 (5.5\%) & 27 (9.9\%) & 249 & 127 (51.0\%) & 93 (37.3\%) & 12 (4.8\%) & 17 (6.8\%) \\
\hline
\end{tabular}

柏科包含了杉科; 红豆杉科包含了三尖杉科。Taxodiaceae in Cupressaceae; Cephalotaxaceae in Taxaceae.

我国西藏西南部产雪松, Flora of China (vol. 4)中已 有记载, 上次评估时遗漏。长苞铁杉(Nothotsuga longibracteata)过去被归入铁杉属(Tsuga), 近些年 来的分子系统学研究证明该属应独立。金柏属是英 国学者Farjon等(2002)在越南发现的新属。近年来, 在我国广西等地发现该属(蒙涛等, 2013)。

柏科柳杉属(Cryptomeria)在中国是否野生存在 争议。《中国植物志》收录柳杉(C. fortunei), 记载该 种产中国福建、浙江和江西; Flora of China将之处 理为变种, 即C. japonica var. sinensis, 增加了其分 布点, 认为该变种分布于福建、江西、四川、云南 和浙江。英国学者Farjon (2010)认为柳杉属原产日 本, 中国的柳杉是从日本引种。柳杉的遗传多样性 研究表明中国分布的柳杉有独特的单倍型(Tsumura et al, 2020)。笔者赞同将中国和日本居群处理为同 一种, 但是不同意Farjon中国产柳杉是从日本引种 的观点, 浙江天目山和福建武夷山均有较老的柳 杉。因此, 本次评估中收录日本柳杉(C. japonica)。

本次评估的 274 个种和种下分类群中, 种级 218 个, 种下分类群96个(含原变种)。与2013版相比, 本 次评估在种级水平上变化较大。2013版总计评估 249 个种和种下分类群, 包括 191 个种和 100 个种下 类群。简单看, 本次评估与2013版相比在学名数量 上多了 25 个, 但这个数字并未反映真实的变化。实 际上, 两次评估名录的共有种和种下分类群 234 个, 本次评估名单比 2013 版增加了 40 个种和种下分类
群, 这 40 个变化中包含了分类等级变更、新类群、 新记录以及2013版遗漏种类等(表2)。

新增物种中一些是2013年评估时遗漏的物种, 如雪松、杉木(Cunninghamia lanceolata)等; 一些是 新分布记录, 如金柏(Xanthocyparis vietnamensis)、 岩生翠柏(Calocedrus rupestris)等; 一些是新的分类 变化, 如蓝麻黄(Ephedra glauca)、松潘圆柏 (Juniperus erectopatens)、昆仑圆柏(J. jarkendensis)、 巨柏(Cupressus gigantea)、剑阁柏木(C. jiangeensis)、 南方红豆杉(Taxus mairei)等; 还有一些是新物种, 如甘肃柏木(Cupressus gansuensis)、灰岩红豆杉 (Taxus calcicola)、河口穗花杉(Amentotaxus hekouensis)、诚氏麻黄(Ephedra chengiae)、中华买 麻藤(Gnetum chinense) 等。中国科学院昆明植物研 究所的龚洵团队在野外调查采集的基础上, 开展了 苏铁属的分子系统学研究, 发现并命名新种陈氏苏 铁(Cycas chenii; Zhou et al, 2015)。四川大学研究人 员近年来对岷江柏木(Cupressus chengiana)进行了 比较深入的研究, 发现分布于白龙江、岷江和大渡 河的柏木遗传上隔离, 岷江居群起源于白龙江居群 和大渡河居群的杂交(Li et al, 2020)。据此, 欧洲学 者将怅江柏木划分为 3 个物种, 即甘肃柏木(白龙江 流域)、岷江柏木(岷江)和大渡河柏木(C. fallax, 大 渡河) (Maerki \& Hoch, 2020)。中国科学院昆明植物 研究所高连明团队对红豆杉属(Taxus)开展了比较 深入的DNA条形码研究, 结果发现中国新增2种红 
表2 2021版和2013版裸子植物红色名录收录物种差异

Table 2 An annotated comparison of species differences between versions 2021 and 2013 of gymnosperm red lists of China

\begin{tabular}{|c|c|c|c|}
\hline $\begin{array}{l}\text { 物种 } \\
\text { Species }\end{array}$ & $\begin{array}{l}\text { 收录情况 } \\
\text { Assessment }\end{array}$ & & $\begin{array}{l}\text { 变化原因 } \\
\text { Reason for change }\end{array}$ \\
\hline 阿萨姆穗花杉 Amentotaxus assamica & 2021 年新增 & New in 2021 & 中国新记录 New record in China \\
\hline 河口穗花杉 Amentotaxus hekouensis & 2021 年新增 & New in 2021 & 新种 New species \\
\hline 岩生翠柏 Calocedrus rupestris & 2021 年新增 & New in 2021 & 中国新记录 New record in China \\
\hline 雪松 Cedrus deodara & 2021 年新增 & New in 2021 & 2013 版遗漏 Missed in 2013 \\
\hline 杉木 Cunninghamia lanceolata & 2021 年新增 & New in 2021 & 2013 版遗漏 Missed in 2013 \\
\hline 不丹柏木 Cupressus cashmeriana & 2021 年新增 & New in 2021 & 中国新记录 New record in China \\
\hline 岷江柏木 Cupressus chengiana & 2021 年新增 & New in 2021 & $\begin{array}{l}\text { 岷江居群独立为一种 New taxonomic delimitation } \\
\text { including only the Min River population }\end{array}$ \\
\hline 大渡河柏木 Cupressus fallax & 2021 年新增 & New in 2021 & $\begin{array}{l}\text { 大渡河居群独立为一种 New taxonomic delimitation } \\
\text { including only the Dadu River population }\end{array}$ \\
\hline 甘肃柏木 Cupressus gansuensis & 2021 年新增 & New in 2021 & $\begin{array}{l}\text { 白龙江居群独立为一种 New taxonomic delimitation } \\
\text { including only the Bailong River population }\end{array}$ \\
\hline 巨柏 Cupressus gigantea & 2021 年新增 & New in 2021 & 分类等级变化 Change of taxonomic rank \\
\hline 剑阁柏木 Cupressus jiangeensis & 2021 年新增 & New in 2021 & 分类等级变化 Change of taxonomic rank \\
\hline 陈氏苏铁 Cycas chenii & 2021 年新增 & New in 2021 & 新种 New species \\
\hline 泮水苏铁 Cycas panshuiensis & 2021 年新增 & New in 2021 & 新种 New species \\
\hline 三亚苏铁 Cycas shanyagensis & 2021 年新增 & New in 2021 & 新种 New species \\
\hline 鸡毛松 Dacrycarpus imbricatus & 2021 年新增 & New in 2021 & 分类变化 Taxonomic change \\
\hline 诚氏麻黄 Ephedra chengiae & 2021 年新增 & New in 2021 & 新种 New species \\
\hline 劲直麻黄 Ephedra chengiae var. spinosa & 2021 年新增 & New in 2021 & 新变种 New variety \\
\hline 蓝麻黄 Ephedra glauca & 2021 年新增 & New in 2021 & 2013 版遗漏 Missed in 2013 \\
\hline 中华买麻藤 Gnetum chinense & 2021 年新增 & New in 2021 & 新种 New species \\
\hline 松潘圆柏 Juniperus erectopatens & 2021 年新增 & New in 2021 & 分类等级变化 Change of taxonomic rank \\
\hline 昆仑圆柏 Juniperus jarkendensis & 2021 年新增 & New in 2021 & 分类变化 New classification \\
\hline 玉山刺柏 Juniperus morrisonicola & 2021 年新增 & New in 2021 & 分类变化 Taxonomic change \\
\hline 沙柏 Juniperus sabina var. arenaria & 2021 年新增 & New in 2021 & 分类变化 Taxonomic change \\
\hline 台湾油杉 Keteleeria formosana & 2021 年新增 & New in 2021 & 分类等级变化 Change of taxonomic rank \\
\hline 长苞铁杉 Nothotsuga longibracteata & 2021 年新增 & New in 2021 & 分类归属变化 Change of taxonomic ascription \\
\hline 大果云杉 Picea asperata var. ponderosa & 2021 年新增 & New in 2021 & 分类变化 Nomenclatural change \\
\hline 乔松 Pinus wallichiana & 2021 年新增 & New in 2021 & 2013 版遗漏 Missed in 2013 \\
\hline 柱冠罗汉松 Podocarpus chingianus & 2021 年新增 & New in 2021 & 中国新记录 New record in China \\
\hline 簇花罗汉松 Podocarpus fasciculus & 2021 年新增 & New in 2021 & 中国新记录 New record in China \\
\hline 虎克罗汉松 Podocarpus hookeri & 2021 年新增 & New in 2021 & 中国新记录 New record in China \\
\hline 小叶罗汉松 Podocarpus pilgeri & 2021 年新增 & New in 2021 & 中国新记录 New record in China \\
\hline 鲁菲罗汉松 Podocarpus rumphiii & 2021 年新增 & New in 2021 & 中国新记录 New record in China \\
\hline 亚热带罗汉松 Podocarpus subtropicalis & 2021 年新增 & New in 2021 & 中国新记录 New record in China \\
\hline 灰岩红豆杉 Taxus calcicola & 2021 年新增 & New in 2021 & 新种 New species \\
\hline 红豆杉 Taxus chinensis & 2021 年新增 & New in 2021 & 分类等级变化 Change of taxonomic rank \\
\hline 密叶红豆杉 Taxus contorta & 2021 年新增 & New in 2021 & 学名变化 Nomenclatural change \\
\hline 佛洛林红豆杉 Taxus florinii & 2021 年新增 & New in 2021 & 分类变化 New classification \\
\hline 南方红豆杉 Taxus mairei & 2021 年新增 & New in 2021 & 分类等级变化 Change of taxonomic rank \\
\hline 喜马拉雅红豆杉 Taxus wallichiana & 2021 年新增 & New in 2021 & 分类等级变化 Change of taxonomic rank \\
\hline 金柏 Xanthocyparis vietnamensis & 2021 年新增 & New in 2021 & 中国新记录 New record in China \\
\hline 岷江柏木原变种 Cupressus chengiana var. chengiana & 2013 年收录 & Included in 2013 & 异名, 分类等级变化 Change of taxonomic rank \\
\hline 剑阁柏木 Cupressus chengiana var. jiangeensis & 2013 年收录 & Included in 2013 & 异名 Synonym of Cupressus jiangeensis \\
\hline
\end{tabular}


表2 (续) Table 2 (continued)

\begin{tabular}{lll}
\hline Species & 收录情况 & 变化原因 \\
Spsessment & Reason for change \\
\hline 巨柏 Cupressus torulosa var. gigantea & 2013 年收录 Included in 2013 异名 Synonym of Cupressus gigantea \\
葫芦苏铁 Cycas changjiangensis & 2013 年收录 Included in 2013 异名 Synonym of Cycas taiwaniana \\
仙湖苏铁 Cycas fairylakea & 2013 年收录 Included in 2013 异名 Synonym of Cycas szechuanensis \\
鸡毛松 Dacrycarpus imbricatus var. patulus & 2013 年收录 Included in 2013 异名 Synonym of Dacrycarpus imbricatus var. imbricatus \\
巨子买麻藤 Gnetum giganteum & 2013 年收录 Included in 2013 异名 Synonym of Gnetum pendulum \\
细柄买麻藤 Gnetum gracilipes & 2013 年收录 Included in 2013 异名 Synonym of Gnetum pendulum \\
海南买麻藤 Gnetum hainanense & 2013 年收录 Included in 2013 异名 Synonym of Gnetum luofuense \\
台湾油杉 Keteleeria davidiana var. formosana & 2013 年收录 Included in 2013 异名 Synonym of Keteleeria formosana \\
密叶红豆杉 Taxus fauna & 2013 年收录 Included in 2013 异名 Synonym of Taxus contorta \\
红豆杉 Taxus wallichiana var. chinensis & 2013 年收录 Included in 2013 异名 Synonym of Taxus chinensis \\
南方红豆杉 Taxus wallichiana var. mairei & 2013 年收录 Included in 2013 异名 Synonym of Taxus mairei \\
喜马拉雅红豆杉 Taxus wallichiana var. wallichiana & 2013 年收录 Included in 2013 异名 Synonym of Taxus wallichiana \\
长苞铁杉 Tsuga longibracteata & 2013 年收录 Included in 2013 异名 Synonym of Nothotsuga longibracteata \\
\hline
\end{tabular}

豆杉属植物, 即佛洛林红豆杉(Taxus florinii)和灰岩 红豆杉(Möller et al, 2013)。

2013版名录中有 15 个种和种下分类群学名未 包含在本次评估名单中(表2)。它们要么被处理为异 名, 如葫芦苏铁(Cycas changjiangensis) 和陵水苏铁 (C. lingshuigensis)被并入闽粤苏铁 (C. taiwaniana), 仙湖苏铁被并入四川苏铁(C. szechuanensis, Feng et al, 2021), 细柄买麻藤(Gnetum gracilipes)和巨子买 麻藤(G. giganteum) 并入垂子买麻藤 (G. pendulum), 而海南买麻藤 (G. hainanense) 并入罗浮买麻藤 ( $G$. luofuense) (Hou et al, 2016); 要么学名等级发生了 变化, 如: Cupressus chengiana var. jiangeensis ( $\equiv C$. jiangeensis)、C. torulosa var. gigantea ( $\equiv$ C. gigantea)、Keteleeria davidiana var. formosana ( $\equiv K$. formosana)、Taxus wallichiana var. chinensis ( $\equiv T$. chinensis)、T. wallichiana var. mairei (三T. mairei)、 T. wallichiana var. wallichiana ( $\equiv T$. wallichiana); 要 么学名发生了变更, 如： T. fuana $(=T$. wallichiana)、Tsuga longibracteata (三Nothotsuga longibracteata)。这些变化一方面表明裸子植物分类 学研究依然比较活跃, 尤其是新的技术和数据对改 变前人的分类学认知和对新分类群的确认起着重 要的作用。另一方面也表明, 尽管与其他植物大门 类相比, 裸子植物物种多样性较低, 但仍存在不少 分类学疑难问题待解决。研究人员近年来对红豆杉 属、柏木属(Cupressus)和买麻藤属(Gnetum)的分类
学研究比较典型, 解决了不少问题, 但是裸子植物 中其他一些疑难类群, 如松科的松属、云杉属和冷 杉属以及柏科的刺柏属和红豆杉科的三尖杉属 (Cephalotaxus)等, 也需要开展DNA 条形码方面的 研究。

\section{2 国产裸子植物的濒危现状}

本次评估的 274 个分类群中, 极危的有 30 种(占 评估总数的 $10.9 \%)$, 濒危 45 种 (16.4\%), 易危 64 种 (23.4\%), 近危 15 种 (5.5\%), 无危93种(33.9\%), 数据 缺乏27种(9.9\%), 受威胁物种(极危、濒危和易危) 总计 139种, 占总评估种数的 $50.7 \%$ (表1)。2013版红 色名录评估的 249 个分类群中, 极危的有 28 种, 濒 危 39 种, 易危 60 种, 近危 12 种, 无危 93 种, 数据缺 乏17种。受威胁物种(极危、濒危和易危)总计 127 种, 占总评估种数的 $51.0 \%$ 。与 2013 版相比, 本次评估的 受威胁程度基本没变, 无危种类数量也基本一致, 但数据缺乏种类略有增加 $(9.9 \%$, 表1), 新增种类中 阿萨姆穗花杉(Amentotaxus assamica)、柱冠罗汉松 (Podocarpus chingianus)、虎克罗汉松(P. hookeri)、 鲁菲罗汉松 ( $P$. rumphiii) 和亚热带罗汉松 $(P$. subtropicalis) 等缺乏数据, 导致数据缺乏比例略微 上升。分科比较来看, 中国松科物种数量最多(121 种), 受威胁物种数量也多达 52 种; 从相对数量看, 苏铁科(95.7\%)、银杏科(100.0\%)、红豆杉科(81.5\%) 和罗汉松科(68.4\%)是处于受威胁最严重的 4 个科; 柏科(43.6\%)和松科(44.4\%)受威胁程度接近; 盖子 
植物类(麻黄科和买麻藤科)受威胁程度最低(表1)。

我国裸子植物的受威胁物种比例达 $50.7 \%$, 这 远高于高等植物受威胁物种整体比例(10.8\%; 覃海 宁等, 2017)。造成裸子植物受威胁物种比例较高的 原因可能有如下几点:

第一, 我国裸子植物子遗和特有种类较多, 新 老并存, 这些物种由于自身属性易濒危。第四纪以 来北半球冰期、间冰期交替, 导致很多原本在北半 球广布的裸子植物南迁或灭绝。我国地形特殊, 三 级台地及东西向山脉走向阻挡了来自北方的冰川, 使得我国南部尤其是西南部保存了很多子遗植物, 如银杏、台湾杉(Taiwania cryptomerioides)、杉木、 水杉、水松(Glyptostrobus pensilis)、柳杉、冷杉(Abies spp.)、崖柏(Thuja sutchuenensis)等, 甚至有一些极 小种群, 如: 百山祖冷杉(Abies beshanzuensis)、巧家 五针松(Pinus squamata) 等。这些子遗物种为我国特 有或近特有。一些新特有物种也容易濒危。我国西 南横断山区和青藏高原地区山脉纵横, 新第三纪以 来山脉快速隆升导致我国地理环境和全国水热分 布极不均衡, 形成东部季风区、西北干旱区和西南 高原区, 高原隆起过程使得一些植物类群快速辐射 分化, 形成了很多新物种。西南地区是我国裸子植 物分布比较集中的地区, 如冷杉属、云杉属、刺柏 属、柏木属等(吕丽莎等, 2018), 包含了很多新分化 形成的特有物种。本次评估的 274 个种和种下分类 群中, 特有种类多达 151 种, 占总种数的 $55.1 \%$ 。这 些子遗和特有植物的竞争能力较弱, 对环境变化比 较敏感, 容易致危。横断山区和雅鲁藏布江中下游 及大峡谷有多处梯级水电站建设和开发, 导致当地 小生境水热条件变化, 致使生长在这些地方的裸子 植物种类濒危, 如: 大渡河上游到康定市之间已建 成或正在修建的梯级水电站将对该地区分布的大 渡河柏木(岷江柏木大渡河居群)产生威胁; 雅鲁藏 布江大峡谷拟建水电站将对朗县至米林段集中分 布的最大的巨柏种群有威胁, 应根据其遗传多样性 采取保护措施(扎西次仁, 2008)。

第二, 资源过度利用仍是物种濒危的重要因 素。20世纪80、90年代, 苏铁类植物野生资源遭到 极大的破坏, 很多野生种群消失。攀枝花苏铁 (Cycas panzhihuaensis) 曾在金沙江干热河谷有比较 广的分布, 因攀枝花钢厂的建设而在周边开矿, 对 野生种群造成了破坏。20世纪60年代初期, 攀枝花
苏铁因树干中含有淀粉而被百姓用来制作凉粉充 饥; 80、90年代园林业兴起, 攀枝花苏铁被贩卖, 损 失严重, 目前仅在四川攀枝花苏铁国家级自然保护 区和云南普渡河自然保护区内分布。尽管国家已出 台各种法律和制度禁止采伐, 但是对苏铁类植物资 源的破坏仍未停止。麻黄属植物是传统中药材, 20 年前曾遭到毁灭性的采挖, 物种资源和自然分布遭 到极大破坏, 并导致了西北地区沙漠化加剧。直到 2000年, 国务院发布国务院令(国发〔2000〕13号) (http://www.gov.cn/gongbao/content/2000/content_60 307.htm), 禁止麻黄、甘草和发菜采挖, 这种野蛮采 挖才被遏制。松柏类裸子植物材质较好, 在西南地 区是建筑和取暖的重要来源, 砍伐情况很难制止。 罗汉松科植物具非典型球果, 因形状似佛教中的罗 汉而得名。笔者近年来在野外调查时发现, 由于宗 教信仰和迷信思想, 我国南方地区民众对罗汉松科 植物野生资源的破坏比较严重, 一些罗汉松科植物 要么被移栽到自家庭院, 以驱邪和镇宅, 要么被买 卖以获得经济利益。一些新建公园里栽植的比较老 龄的罗汉松可能是直接或间接由野外采挖获得。

第三, 栖息地丧失也是导致物种濒危的重要因 素。例如, 麻黄属植物普遍喜干旱、喜光, 笔者多 年对麻黄属植物的调查发现, 植被变好导致该属一 些种类的分布区收缩。斑子麻黄 (Ephedra rhytidosperma) 是贺兰山特有种, 在贺兰山低山滩地 生长。近十来年, 宁夏回族自治区对贺兰山东麓滩 地进行植树造林并建立了大量的葡萄酒酒庄, 侵占 了斑子麻黄的分布区, 导致该种的自然分布区缩 小。另外, 1998年笔者第一次访问新疆乌鲁木齐红 山公园时, 公园内有细子麻黄(E. regeliana)分布。随 着公园的建设和绿化, 细子麻黄逐步退出公园。至 2008年时, 该种仅在公园围栏外部的石头缝隙和峭 壁可见。

第四, 碳排放导致全球变暖是工业革命以来的 重要变化, 而全球变暖导致病虫害发生频繁。松材 线虫病又称松枯萎病, 是一种毁灭性虫害, 由外来 种松材线虫(Bursaphelenchus xylophilus)感染引起; 松材线虫通过松墨天牛(Monochamus alternatus)对 松属植物进行侵染(高瑞贺等, 2019)。被松材线虫感 染后的松树针叶呈黄褐色或红褐色, 萎䔄下垂, 树 脂分泌停止, 病树整株干枯死亡, 最终腐烂。松材 线虫原产美洲, 传入中国以来对南方主要造林树种 
杨永：中国裸子植物红色名录评估(2021版) 1605

马尾松(Pinus massoniana)等针叶树造成了致命的 破坏, 随着全球气候变暖, 松材线虫病向北扩张, 并导致东北亚和欧洲针叶树的大面积死亡(Calvão et al, 2019; 高瑞贺等, 2019)。

\section{3 展望}

尽管裸子植物分类学研究在过去 10 年中有了 不少新进展, 但是种的分类地位不确定和物种的自 然生存数据缺乏仍是限制裸子植物红色名录评估 的主要原因。在分类方面, 松属、冷杉属、云杉属、 三尖杉属、买麻藤属等的分类还需要开展深入研 究。分类问题存在的原因包括: (1)物种特征变异式 样复杂; (2)缺少针对性的野外调查和研究。红豆杉 属的分类方案应该被用于其他疑难属的分类研究 中。还有些种类在中国是否有自然分布尚不确定, 如水松、柳杉、高大陆均松(Dacrydium elatum)等。 水松在越南有比较确定的野生分布, 而在中国, 水 松的遗传多样性普遍很低, 有可能是快速扩张, 也 有可能是人工引种。《中国植物志》和Flora of China 均记载我国只有一种陆均松 (D. pectinatum), 分布 在海南。Farjon (2010)认为中国广西有高大陆均松, 但目前我们还没有掌握该种在广西分布的实际证 据。银杏的原产地有过较长时期的争论, 浙江大学 对银杏开展了谱系地理学研究, 证明该种的原产地 在中国西南、南岭山脉及东部浙江天目山, 均为冰 期避难地(Zhao et al, 2019)。柳杉也迫切需要开展类 似的研究，以明确其自然分布问题。

数据缺乏仍严重制约着裸子植物的红色名录 评估工作。本次评估中有27种(9.9\%)裸子植物缺乏 数据, 其中刺柏属最多, 有 8 种, 云杉属和松属均有 5种, 罗汉松属4种, 麻黄属2种, 买麻藤属、落叶松 属和苏铁属各 1 种。裸子植物种类虽少, 但它们在我 国森林生态系统中起着重要作用。为了准确了解这 一类植物的濒危状况, 非常有必要启动类似兰科那 样的全国性普查项目, 以摸清我国裸子植物的物种 分布情况和致危因素。在野外调查基础上, 一方面 开展分类学研究, 摸清疑难属种的分类问题, 另一 方面基于新获得的数据进行新的红色名录评估, 通 过这种清查工作还可以摸清一些种类在我国是否 有野生分布，如高大陆均松。
杨永 (D) https://orcid.org/0000-0001-7763-5133

\section{参考文献}

Calvão T, Duarte CM, Pimentel CS (2019) Climate and landscape patterns of pine forest decline after invasion by the pinewood nematode. Forest Ecology and Management, 433, 43-51.

Christenhusz MJM, Reveal JL, Farjon A, Gardner MF, Mill RR, Chase MW (2011) A new classification and linear sequence of extant gymnosperms. Phytotaxa, 19, 55-70.

Farjon A (2010) A Handbook of the World's Conifers. Brill, Leiden \& Boston.

Farjon A, Hiep NT, Harder DK, Loc PK, Averyanov L (2002) A new genus and species in Cupressaceae (Coniferales) from Northern Vietnam, Xanthocyparis vietnamensis. Novon, 12, 179-189.

Feng XY, Wang XH, Chiang YC, Jian SG, Gong X (2021) Species delimitation with distinct methods based on molecular data to elucidate species boundaries in the Cycas taiwaniana complex (Cycadaceae). Taxon, 70, 477-491.

Gao RH, Ji WR, Li H, Shi J (2019) The relationship between pine wilt disease occurrence and climatic variation. Journal of Shanxi Agricultural University (Natural Science Edition), 39(5), 32-40. (in Chinese with English abstract) [高瑞贺, 冀卫荣, 李宏, 石娟 (2019) 松材线虫病疫情指数与气候 因素之间的关系. 山西农业大学学报(自然科学版), 39(5), 32-40.]

Hou C, Wikström N, Strijk JS, Rydin C (2016) Resolving phylogenetic relationships and species delimitations in closely related gymnosperms using high-throughput NGS, Sanger sequencing and morphology. Plant Systematics and Evolution, 302, 1345-1365.

IUCN (International Union for Conservation of Nature) (2012) IUCN Red List Categories and Criteria: Version 3.1. 2nd edn. Gland, Switzerland \& Cambridge, UK.

Leslie AB, Beaulieu JM, Rai HS, Crane PR, Donoghue MJ, Mathews S (2012) Hemisphere-scale differences in conifer evolutionary dynamics. Proceedings of the National Academy of Sciences, USA, 109, 16217-16221.

Li JL, Milne RI, Ru DF, Miao JB, Tao WJ, Zhang L, Xu JJ, Liu JQ, Mao KS (2020) Allopatric divergence and hybridization within Cupressus chengiana (Cupressaceae), a threatened conifer in the northern Hengduan Mountains of Western China. Molecular Ecology, 29, 1250-1266.

Lü LS, Cai HY, Yang Y, Wang ZH, Zeng H (2018) Geographic patterns and environmental determinants of gymnosperm species diversity in China. Biodiversity Science, 26, 1133-1146. (in Chinese with English abstract) [吕丽莎, 蔡 宏宇, 杨永, 王志恒, 曾辉 (2018) 中国裸子植物的物种 多样性格局及其影响因子. 生物多样性, 26, 1133-1146.]

Maerki D, Hoch J (2020) Taxonomy of the cypresses of Sichuan and Gansu. Bulletin of the Cupressus Conservation Project, 9, 3-12.

\section{ORCID}


Meng T, Peng RC, Zhong GF, You ZJ, Tan WN, Xu WB (2013) Xanthocyparis Farjon \& Hiep, a newly recorded genus of Cupressaceae from China. Guihaia, 33, 388-391. (in Chinese) [蒙涛, 彭日成, 钟国芳, 游旨价, 谭卫宁, 许 为斌 (2013) 黄金柏属一中国柏科一新记录属. 广西 植物, 33, 388-391.]

Möller M, Gao LM, Mill RR, Liu J, Zhang DQ, Poudel RC, Li DZ (2013) A multidisciplinary approach reveals hidden taxonomic diversity in the morphologically challenging Taxus wallichiana complex. Taxon, 62, 1161-1177.

Nagalingum NS, Marshall CR, Quental TB, Rai HS, Little DP, Mathews S (2011) Recent synchronous radiation of a living fossil. Science, 334, 796-799.

Tashi Tsering (2008) Studies on Genetic Diversity and Variation in Essential Oil of Tibetan Giant Cypress, Cupressus gigantea, and Implications for Its Conservation Biology. PhD dissertation. Fudan University, Shanghai. (in Chinese with English abstract) [扎西次仁 (2008) 西藏巨 柏(Cupressus gigantea)的遗传多样性与精油化学成分变 异及其保护生物学意义. 博士学位论文, 复旦大学, 上 海.]

Tsumura Y, Kimura M, Nakao K, Uchiyama K, Ujino-Ihara T,
Wen YF, Tong ZK, Han WJ (2020) Effects of the last glacial period on genetic diversity and genetic differentiation in Cryptomeria japonica in East Asia. Tree Genetics \& Genomes, 16, 19.

Yang Y, Wang ZH, Xu XT (2017) Taxonomy and Distribution of Global Gymnosperms. Shanghai Scientific \& Technical Publishers, Shanghai. (in Chinese) [杨永, 王志恒, 徐晓婷 (2017) 世界裸子植物的分类和地理分布. 上海科学技术 出版社, 上海.]

Zhao YP, Fan GY, Yin PP, Sun S, Li N, Hong XN, Hu G, Zhang H, Zhang FM, Han JD, Hao YJ, Xu QW, Yang XW, Xia WJ, Chen WB, Lin HY, Zhang R, Chen J, Zheng XM, Lee SMY, Lee JK, Uehara K, Wang J, Yang HM, Fu CX, Liu X, Xu X, Ge S (2019) Resequencing 545 ginkgo genomes across the world reveals the evolutionary history of the living fossil. Nature Communications, 10, 4201.

Zhou W, Guan MM, Gong X (2015) Cycas chenii (Cycadaceae), a new species from China, and its phylogenetic position. Journal of Systematics and Evolution, 53, 489-498.

(责任编委: 严岳鸿 责任编辑: 黄祥忠)

\section{附录 Supplementary Material}

附录1 中国裸子植物红色名录(2021版)

Appendix 1 An updated red list of gymnosperms from China (Version 2021)

https://www.biodiversity-science.net/fileup/PDF/2021342-1.pdf 
杨永 (2021) 中国裸子植物红色名录评估(2021 版). 生物多样性, 29, 1599-1606. https://www.biodiversityscience.net/CN/10.17520/biods.2021342

附录1 中国裸子植物红色名录(2021版)

Appendix 1 An updated red list of gymnosperms from China (Version 2021)

\begin{tabular}{|c|c|c|c|c|}
\hline $\begin{array}{l}\text { 中文科名 } \\
\text { Family name_CN }\end{array}$ & $\begin{array}{l}\text { 拉丁科名 } \\
\text { Family name_Latin }\end{array}$ & $\begin{array}{l}\text { 中文种名 } \\
\text { Species name_CN }\end{array}$ & $\begin{array}{l}\text { 拉丁种名 } \\
\text { Species name_Latin }\end{array}$ & $\begin{array}{l}\text { 濒危等级 } \\
\text { Endangered category }\end{array}$ \\
\hline 柏科 & Cupressaceae & 台湾翠柏 & Calocedrus macrolepis var. formosana & VU \\
\hline 柏科 & Cupressaceae & 翠柏 & Calocedrus macrolepis var. macrolepis & LC \\
\hline 柏科 & Cupressaceae & 岩生翠柏 & Calocedrus rupestris & $\mathrm{EN}$ \\
\hline 柏科 & Cupressaceae & 红桧 & Chamaecyparis formosensis & $\mathrm{EN}$ \\
\hline 柏科 & Cupressaceae & 台湾扁柏 & Chamaecyparis obtusa var. formosana & VU \\
\hline 杉科 & Cupressaceae & 日本柳杉 & Cryptomeria japonica & LC \\
\hline 杉科 & Cupressaceae & 台湾杉木 & Cunninghamia konishii & VU \\
\hline 柏科 & Cupressaceae & 杉木 & Cunninghamia lanceolata & LC \\
\hline 柏科 & Cupressaceae & 不丹柏木 & Cupressus cashmeriana & NT \\
\hline 柏科 & Cupressaceae & 岷江柏木 & Cupressus chengiana & $\mathrm{CR}$ \\
\hline 柏科 & Cupressaceae & 干香柏 & Cupressus duclouxiana & NT \\
\hline 柏科 & Cupressaceae & 大渡河柏木 & Cupressus fallax & $\mathrm{CR}$ \\
\hline 柏科 & Cupressaceae & 柏木 & Cupressus funebris & LC \\
\hline 柏科 & Cupressaceae & 甘肃柏木 & Cupressus gansuensis & $\mathrm{CR}$ \\
\hline 柏科 & Cupressaceae & 巨柏 & Cupressus gigantea & $\mathrm{EN}$ \\
\hline 柏科 & Cupressaceae & 剑阁柏木 & Cupressus jiangeensis & $\mathrm{CR}$ \\
\hline 柏科 & Cupressaceae & 西藏柏木 & Cupressus torulosa var. torulosa & $\mathrm{EN}$ \\
\hline 柏科 & Cupressaceae & 福建柏 & Fokienia hodginsii & $\mathrm{VU}$ \\
\hline 杉科 & Cupressaceae & 水松 & Glyptostrobus pensilis & VU \\
\hline 柏科 & Cupressaceae & 圆柏 & Juniperus chinensis var. chinensis & LC \\
\hline 柏科 & Cupressaceae & 偃柏 & Juniperus chinensis var. sargentii & VU \\
\hline 柏科 & Cupressaceae & 清水圆柏 & Juniperus chinensis var. tsukushiensis & $\mathrm{EN}$ \\
\hline 柏科 & Cupressaceae & 密枝圆柏 & Juniperus convallium var. convallium & $\mathrm{LC}$ \\
\hline 柏科 & Cupressaceae & 小子圆柏 & Juniperus convallium var. microsperma & $\mathrm{LC}$ \\
\hline 柏科 & Cupressaceae & 松潘圆柏 & Juniperus erectopatens & $\mathrm{DD}$ \\
\hline 柏科 & Cupressaceae & 刺柏 & Juniperus formosana & $\mathrm{LC}$ \\
\hline 柏科 & Cupressaceae & 昆明柏 & Juniperus gaussenii & $\mathrm{DD}$ \\
\hline 柏科 & Cupressaceae & 簇生滇藏方枝柏 & Juniperus indica var. caespitosa & $\mathrm{DD}$ \\
\hline 柏科 & Cupressaceae & 滇藏方枝柏 & Juniperus indica var. indica & $\mathrm{DD}$ \\
\hline 柏科 & Cupressaceae & 昆仑圆柏 & Juniperus jarkendensis & $\mathrm{DD}$ \\
\hline 柏科 & Cupressaceae & 塔枝圆柏 & Juniperus komarovii & LC \\
\hline 柏科 & Cupressaceae & 玉山刺柏 & Juniperus morrisonicola & $\mathrm{DD}$ \\
\hline 柏科 & Cupressaceae & 万钧柏 & Juniperus pingii var. chengii & $\mathrm{VU}$ \\
\hline 柏科 & Cupressaceae & 西藏香柏 & Juniperus pingii var. miehei & $\mathrm{DD}$ \\
\hline 柏科 & Cupressaceae & 垂枝香柏 & Juniperus pingii var. pingii & LC \\
\hline 柏科 & Cupressaceae & 香柏 & Juniperus pingii var. wilsonii & LC \\
\hline 柏科 & Cupressaceae & 祁连圆柏 & Juniperus przewalskii & LC \\
\hline
\end{tabular}


杨永 (2021) 中国裸子植物红色名录评估(2021 版). 生物多样性, 29, 1599-1606. https://www.biodiversityscience.net/CN/10.17520/biods.2021342

\begin{tabular}{|c|c|c|c|c|}
\hline $\begin{array}{l}\text { 中文科名 } \\
\text { Family name_CN }\end{array}$ & $\begin{array}{l}\text { 拉丁科名 } \\
\text { Family name_Latin }\end{array}$ & $\begin{array}{l}\text { 中文种名 } \\
\text { Species name_CN }\end{array}$ & $\begin{array}{l}\text { 拉丁种名 } \\
\text { Species name_Latin }\end{array}$ & $\begin{array}{l}\text { 濒危等级 } \\
\text { Endangered category }\end{array}$ \\
\hline 柏科 & Cupressaceae & 新疆方枝柏 & Juniperus pseudosabina & $\mathrm{LC}$ \\
\hline 柏科 & Cupressaceae & 小果垂枝柏 & Juniperus recurva var. coxii & VU \\
\hline 柏科 & Cupressaceae & 垂枝柏 & Juniperus recurva var. recurva & NT \\
\hline 柏科 & Cupressaceae & 杜松 & Juniperus rigida & NT \\
\hline 柏科 & Cupressaceae & 沙柏 & Juniperus sabina var. arenaria & $\mathrm{LC}$ \\
\hline 柏科 & Cupressaceae & 兴安圆柏 & Juniperus sabina var. davurica & $\mathrm{DD}$ \\
\hline 柏科 & Cupressaceae & 叉子圆柏 & Juniperus sabina var. sabina & $\mathrm{LC}$ \\
\hline 柏科 & Cupressaceae & 方枝柏 & Juniperus saltuaria & $\mathrm{LC}$ \\
\hline 柏科 & Cupressaceae & 昆仑多子柏 & Juniperus semiglobosa & VU \\
\hline 柏科 & Cupressaceae & 西伯利亚刺柏 & Juniperus sibirica & $\mathrm{LC}$ \\
\hline 柏科 & Cupressaceae & 高山柏 & Juniperus squamata & $\mathrm{LC}$ \\
\hline 柏科 & Cupressaceae & 大果圆柏 & Juniperus tibetica & VU \\
\hline 杉科 & Cupressaceae & 水杉 & Metasequoia glyptostroboides & EN \\
\hline 柏科 & Cupressaceae & 侧柏 & Platycladus orientalis & $\mathrm{LC}$ \\
\hline 杉科 & Cupressaceae & 台湾杉 & Taiwania cryptomerioides & VU \\
\hline 柏科 & Cupressaceae & 朝鲜崖柏 & Thuja koraiensis & $\mathrm{CR}$ \\
\hline 柏科 & Cupressaceae & 崖柏 & Thuja sutchuenensis & $\mathrm{EN}$ \\
\hline 柏科 & Cupressaceae & 越南金柏 & Xanthocyparis vietnamensis & $\mathrm{CR}$ \\
\hline 苏铁科 & Cycadaceae & 宽叶苏铁 & Cycas balansae & $\mathrm{EN}$ \\
\hline 苏铁科 & Cycadaceae & 叉叶苏铁 & Cycas bifida & $\mathrm{CR}$ \\
\hline 苏铁科 & Cycadaceae & 陈氏苏铁 & Cycas chenii & $\mathrm{EN}$ \\
\hline 苏铁科 & Cycadaceae & 德保苏铁 & Cycas debaoensis & $\mathrm{CR}$ \\
\hline 苏铁科 & Cycadaceae & 滇南苏铁 & Cycas diannanensis & $\mathrm{CR}$ \\
\hline 苏铁科 & Cycadaceae & 长叶苏铁 & Cycas dolichophylla & $\mathrm{EN}$ \\
\hline 苏铁科 & Cycadaceae & 锈毛苏铁 & Cycas ferruginea & VU \\
\hline 苏铁科 & Cycadaceae & 贵州苏铁 & Cycas guizhouensis & $\mathrm{CR}$ \\
\hline 苏铁科 & Cycadaceae & 海南苏铁 & Cycas hainanensis & EN \\
\hline 苏铁科 & Cycadaceae & 灰干苏铁 & Cycas hongheensis & $\mathrm{CR}$ \\
\hline 苏铁科 & Cycadaceae & 多羽叉叶苏铁 & Cycas multifrondis & $\mathrm{CR}$ \\
\hline 苏铁科 & Cycadaceae & 多岐苏铁 & Cycas multipinnata & EN \\
\hline 苏铁科 & Cycadaceae & 纤细苏铁 & Cycas panshuiensis & $\mathrm{DD}$ \\
\hline 苏铁科 & Cycadaceae & 攀枝花苏铁 & Cycas panzhihuaensis & $\mathrm{EN}$ \\
\hline 苏铁科 & Cycadaceae & 篦齿苏铁 & Cycas pectinata & $\mathrm{VU}$ \\
\hline 苏铁科 & Cycadaceae & 苏铁 & Cycas revoluta & $\mathrm{CR}$ \\
\hline 苏铁科 & Cycadaceae & 叉孢苏铁 & Cycas segmentifida & $\mathrm{EN}$ \\
\hline 苏铁科 & Cycadaceae & 石山苏铁 & Cycas sexseminifera & EN \\
\hline 苏铁科 & Cycadaceae & 三亚苏铁 & Cycas shanyagensis & $\mathrm{VU}$ \\
\hline 苏铁科 & Cycadaceae & 四川苏铁 & Cycas szechuanensis & $\mathrm{CR}$ \\
\hline 苏铁科 & Cycadaceae & 台东苏铁 & Cycas taitungensis & $\mathrm{CR}$ \\
\hline
\end{tabular}


杨永 (2021) 中国裸子植物红色名录评估(2021 版). 生物多样性, 29, 1599-1606. https://www.biodiversityscience.net/CN/10.17520/biods.2021342

\begin{tabular}{|c|c|c|c|c|}
\hline $\begin{array}{l}\text { 中文科名 } \\
\text { Family name_CN }\end{array}$ & $\begin{array}{l}\text { 拉丁科名 } \\
\text { Family name_Latin }\end{array}$ & $\begin{array}{l}\text { 中文种名 } \\
\text { Species name_CN }\end{array}$ & $\begin{array}{l}\text { 拉丁种名 } \\
\text { Species name_Latin }\end{array}$ & $\begin{array}{l}\text { 濒危等级 } \\
\text { Endangered category }\end{array}$ \\
\hline 苏铁科 & Cycadaceae & 闽南苏铁 & Cycas taiwaniana & EN \\
\hline 苏铁科 & Cycadaceae & 绿春苏铁 & Cycas tanqingii & $\mathrm{EN}$ \\
\hline 麻黄科 & Ephedraceae & 诚氏麻黄 & Ephedra chengiae & DD \\
\hline 麻黄科 & Ephedraceae & 刺枝麻黄 & Ephedra chengiae var. spinosa & $\mathrm{DD}$ \\
\hline 麻黄科 & Ephedraceae & 道孚麻黄 & Ephedra dawuensis & VU \\
\hline 麻黄科 & Ephedraceae & 双穗麻黄 & Ephedra distachya & $\mathrm{LC}$ \\
\hline 麻黄科 & Ephedraceae & 木贼麻黄 & Ephedra equisetina var. equisetina & $\mathrm{LC}$ \\
\hline 麻黄科 & Ephedraceae & 两性木贼麻黄 & Ephedra equisetina var. monoica & $\mathrm{LC}$ \\
\hline 麻黄科 & Ephedraceae & 山岭麻黄 & Ephedra gerardiana & $\mathrm{LC}$ \\
\hline 麻黄科 & Ephedraceae & 蓝麻黄 & Ephedra glauca & NT \\
\hline 麻黄科 & Ephedraceae & 中麻黄 & Ephedra intermedia & NT \\
\hline 麻黄科 & Ephedraceae & 丽江麻黄 & Ephedra likiangensis & $\mathrm{LC}$ \\
\hline 麻黄科 & Ephedraceae & 矮麻黄 & Ephedra minuta & $\mathrm{LC}$ \\
\hline 麻黄科 & Ephedraceae & 单子麻黄 & Ephedra monosperma & $\mathrm{LC}$ \\
\hline 麻黄科 & Ephedraceae & 膜果麻黄 & Ephedra przewalskii & $\mathrm{LC}$ \\
\hline 麻黄科 & Ephedraceae & 细子麻黄 & Ephedra regeliana & $\mathrm{LC}$ \\
\hline 麻黄科 & Ephedraceae & 斑子麻黄 & Ephedra rhytidosperma & EN \\
\hline 麻黄科 & Ephedraceae & 日土麻黄 & Ephedra rituensis & $\mathrm{LC}$ \\
\hline 麻黄科 & Ephedraceae & 藏麻黄 & Ephedra saxatilis & $\mathrm{LC}$ \\
\hline 麻黄科 & Ephedraceae & 草麻黄 & Ephedra sinica & NT \\
\hline 银杏科 & Ginkgoaceae & 银杏 & Ginkgo biloba & $\mathrm{EN}$ \\
\hline 买麻藤科 & Gnetaceae & 球子买麻藤 & Gnetum catasphaericum & $\mathrm{LC}$ \\
\hline 买麻藤科 & Gnetaceae & 中华买麻藤 & Gnetum chinense & $\mathrm{LC}$ \\
\hline 买麻藤科 & Gnetaceae & 灌状买麻藤 & Gnetum gnemon & $\mathrm{DD}$ \\
\hline 买麻藤科 & Gnetaceae & 罗浮买麻藤 & Gnetum luofuense & $\mathrm{LC}$ \\
\hline 买麻藤科 & Gnetaceae & 买麻藤 & Gnetum montanum & $\mathrm{LC}$ \\
\hline 买麻藤科 & Gnetaceae & 小叶买麻藤 & Gnetum parvifolium & $\mathrm{LC}$ \\
\hline 买麻藤科 & Gnetaceae & 垂子买麻藤 & Gnetum pendulum & $\mathrm{LC}$ \\
\hline 松科 & Pinaceae & 百山祖冷杉 & Abies beshanzuensis & $\mathrm{CR}$ \\
\hline 松科 & Pinaceae & 察隅冷杉 & Abies chayuensis & EN \\
\hline 松科 & Pinaceae & 秦岭冷杉 & Abies chensiensis & $\mathrm{VU}$ \\
\hline 松科 & Pinaceae & 苍山冷杉 & Abies delavayi var. delavayi & $\mathrm{LC}$ \\
\hline 松科 & Pinaceae & 墨脱冷杉 & Abies delavayi var. motuoensis & $\mathrm{LC}$ \\
\hline 松科 & Pinaceae & 锡金冷杉 & Abies densa & VU \\
\hline 松科 & Pinaceae & 黄果冷杉 & Abies ernestii var. ernestii & $\mathrm{LC}$ \\
\hline 松科 & Pinaceae & 大黄果冷杉 & Abies ernestii var. salouenensis & $\mathrm{LC}$ \\
\hline 松科 & Pinaceae & 冷杉 & Abies fabri & $\mathrm{LC}$ \\
\hline 松科 & Pinaceae & 梵净山冷杉 & Abies fanjingshanensis & EN \\
\hline 松科 & Pinaceae & 巴山冷杉 & Abies fargesii var. fargesii & $\mathrm{LC}$ \\
\hline
\end{tabular}


杨永 (2021) 中国裸子植物红色名录评估(2021 版). 生物多样性, 29, 1599-1606. https://www.biodiversityscience.net/CN/10.17520/biods.2021342

\begin{tabular}{|c|c|c|c|c|}
\hline $\begin{array}{l}\text { 中文科名 } \\
\text { Family name_CN }\end{array}$ & $\begin{array}{l}\text { 拉丁科名 } \\
\text { Family name_Latin }\end{array}$ & $\begin{array}{l}\text { 中文种名 } \\
\text { Species name_CN }\end{array}$ & $\begin{array}{l}\text { 拉丁种名 } \\
\text { Species name_Latin }\end{array}$ & $\begin{array}{l}\text { 濒危等级 } \\
\text { Endangered category }\end{array}$ \\
\hline 松科 & Pinaceae & 岷江冷杉 & Abies fargesii var. faxoniana & $\mathrm{LC}$ \\
\hline 松科 & Pinaceae & 中甸冷杉 & Abies ferreana var. ferreana & $\mathrm{LC}$ \\
\hline 松科 & Pinaceae & 长苞中甸冷杉 & Abies ferreana var. longibracteata & VU \\
\hline 松科 & Pinaceae & 川滇冷杉 & Abies forrestii & $\mathrm{LC}$ \\
\hline 松科 & Pinaceae & 长苞冷杉 & Abies georgei var. georgei & $\mathrm{LC}$ \\
\hline 松科 & Pinaceae & 急尖长苞冷杉 & Abies georgei var. smithii & $\mathrm{LC}$ \\
\hline 松科 & Pinaceae & 杉松 & Abies holophylla & $\mathrm{LC}$ \\
\hline 松科 & Pinaceae & 台湾冷杉 & Abies kawakamii & $\mathrm{LC}$ \\
\hline 松科 & Pinaceae & 臭冷杉 & Abies nephrolepis & $\mathrm{LC}$ \\
\hline 松科 & Pinaceae & 怒江冷杉 & Abies nukiangensis & VU \\
\hline 松科 & Pinaceae & 紫果冷杉 & Abies recurvata & VU \\
\hline 松科 & Pinaceae & 西伯利亚冷杉 & Abies sibirica & EN \\
\hline 松科 & Pinaceae & 藏冷杉 & Abies spectabilis & VU \\
\hline 松科 & Pinaceae & 鳞皮冷杉 & Abies squamata & VU \\
\hline 松科 & Pinaceae & 元宝山冷杉 & Abies yuanbaoshanensis & $\mathrm{CR}$ \\
\hline 松科 & Pinaceae & 资源冷杉 & Abies ziyuanensis & EN \\
\hline 松科 & Pinaceae & 银杉 & Cathaya argyrophylla & VU \\
\hline 松科 & Pinaceae & 雪松 & Cedrus deodara & VU \\
\hline 松科 & Pinaceae & 黄枝油杉 & Keteleeria davidiana var. calcarea & EN \\
\hline 松科 & Pinaceae & 铁坚油杉 & Keteleeria davidiana var. davidiana & $\mathrm{LC}$ \\
\hline 松科 & Pinaceae & 云南油杉 & Keteleeria evelyniana & NT \\
\hline 松科 & Pinaceae & 台湾油杉 & Keteleeria formosana & $\mathrm{CR}$ \\
\hline 松科 & Pinaceae & 江南油杉 & Keteleeria fortunei var. cyclolepis & $\mathrm{LC}$ \\
\hline 松科 & Pinaceae & 油杉 & Keteleeria fortunei var. fortunei & $\mathrm{VU}$ \\
\hline 松科 & Pinaceae & 矩鳞油杉 & Keteleeria fortunei var. oblonga & $\mathrm{CR}$ \\
\hline 松科 & Pinaceae & 海南油杉 & Keteleeria hainanensis & $\mathrm{VU}$ \\
\hline 松科 & Pinaceae & 柔毛油杉 & Keteleeria pubescens & $\mathrm{VU}$ \\
\hline 松科 & Pinaceae & 落叶松 & Larix gmelinii var. gmelinii & $\mathrm{LC}$ \\
\hline 松科 & Pinaceae & 华北落叶松 & Larix gmelinii var. principis-rupprechtii & $\mathrm{VU}$ \\
\hline 松科 & Pinaceae & 藏红杉 & Larix griffithii & LC \\
\hline 松科 & Pinaceae & 喜马拉雅红杉 & Larix himalaica & LC \\
\hline 松科 & Pinaceae & 贡布红杉 & Larix kongboensis & DD \\
\hline 松科 & Pinaceae & 四川红杉 & Larix mastersiana & $\mathrm{VU}$ \\
\hline 松科 & Pinaceae & 黄花落叶松 & Larix olgensis & LC \\
\hline 松科 & Pinaceae & 大果红杉 & Larix potaninii var. australis & $\mathrm{LC}$ \\
\hline 松科 & Pinaceae & 秦岭红杉 & Larix potaninii var. chinensis & $\mathrm{LC}$ \\
\hline 松科 & Pinaceae & 红杉 & Larix potaninii var. potaninii & LC \\
\hline 松科 & Pinaceae & 新疆落叶松 & Larix sibirica & VU \\
\hline 松科 & Pinaceae & 怒江红杉 & Larix speciosa & NT \\
\hline
\end{tabular}


杨永 (2021) 中国裸子植物红色名录评估(2021 版). 生物多样性, 29, 1599-1606. https://www.biodiversityscience.net/CN/10.17520/biods.2021342

\begin{tabular}{|c|c|c|c|c|}
\hline $\begin{array}{l}\text { 中文科名 } \\
\text { Family name_CN }\end{array}$ & $\begin{array}{l}\text { 拉丁科名 } \\
\text { Family name_Latin }\end{array}$ & $\begin{array}{l}\text { 中文种名 } \\
\text { Species name_CN }\end{array}$ & $\begin{array}{l}\text { 拉丁种名 } \\
\text { Species name_Latin }\end{array}$ & $\begin{array}{l}\text { 濒危等级 } \\
\text { Endangered category }\end{array}$ \\
\hline 松科 & Pinaceae & 长苞铁杉 & Nothotsuga longibracteata & VU \\
\hline 松科 & Pinaceae & 云杉 & Picea asperata var. asperata & $\mathrm{LC}$ \\
\hline 松科 & Pinaceae & 白皮云杉 & Picea asperata var. aurantiaca & $\mathrm{DD}$ \\
\hline 松科 & Pinaceae & 裂鳞云杉 & Picea asperata var. heterolepis & $\mathrm{DD}$ \\
\hline 松科 & Pinaceae & 大果云杉 & Picea asperata var. ponderosa & $\mathrm{CR}$ \\
\hline 松科 & Pinaceae & 麦吊云杉 & Picea brachytyla var. brachytyla & $\mathrm{LC}$ \\
\hline 松科 & Pinaceae & 油麦吊云杉 & Picea brachytyla var. complanata & $\mathrm{LC}$ \\
\hline 松科 & Pinaceae & 青海云杉 & Picea crassifolia & $\mathrm{LC}$ \\
\hline 松科 & Pinaceae & 缅甸云杉 & Picea farreri & $\mathrm{DD}$ \\
\hline 松科 & Pinaceae & 鱼鳞云杉 & Picea jezoensis var. jezoensis & $\mathrm{LC}$ \\
\hline 松科 & Pinaceae & 长白鱼鳞云杉 & Picea jezoensis var. komarovii & $\mathrm{LC}$ \\
\hline 松科 & Pinaceae & 兴安鱼鳞云杉 & Picea jezoensis var. microsperma & $\mathrm{DD}$ \\
\hline 松科 & Pinaceae & 红皮云杉 & Picea koraiensis & $\mathrm{LC}$ \\
\hline 松科 & Pinaceae & 黄果云杉 & Picea likiangensis var. hirtella & VU \\
\hline 松科 & Pinaceae & 丽江云杉 & Picea likiangensis var. likiangensis & $\mathrm{LC}$ \\
\hline 松科 & Pinaceae & 林芝云杉 & Picea likiangensis var. linzhiensis & NT \\
\hline 松科 & Pinaceae & 川西云杉 & Picea likiangensis var. rubescens & $\mathrm{LC}$ \\
\hline 松科 & Pinaceae & 白杆 & Picea meyeri & NT \\
\hline 松科 & Pinaceae & 康定云杉 & Picea montigena & $\mathrm{CR}$ \\
\hline 松科 & Pinaceae & 台湾云杉 & Picea morrisonicola & $\mathrm{EN}$ \\
\hline 松科 & Pinaceae & 大果青杆 & Picea neoveitchii & NT \\
\hline 松科 & Pinaceae & 新疆云杉 & Picea obovata & $\mathrm{LC}$ \\
\hline 松科 & Pinaceae & 紫果云杉 & Picea purpurea & $\mathrm{LC}$ \\
\hline 松科 & Pinaceae & 雪岭杉 & Picea schrenkiana & LC \\
\hline 松科 & Pinaceae & 长叶云杉 & Picea smithiana & $\mathrm{EN}$ \\
\hline 松科 & Pinaceae & 西藏云杉 & Picea spinulosa & DD \\
\hline 松科 & Pinaceae & 青扦 & Picea wilsonii & $\mathrm{LC}$ \\
\hline 松科 & Pinaceae & 华山松 & Pinus armandii var. armandii & $\mathrm{LC}$ \\
\hline 松科 & Pinaceae & 台湾果松 & Pinus armandii var. mastersiana & $\mathrm{VU}$ \\
\hline 松科 & Pinaceae & 不丹松 & Pinus bhutanica & LC \\
\hline 松科 & Pinaceae & 白皮松 & Pinus bungeana & EN \\
\hline 松科 & Pinaceae & 高山松 & Pinus densata & $\mathrm{LC}$ \\
\hline 松科 & Pinaceae & 赤松 & Pinus densiflora var. densiflora & $\mathrm{LC}$ \\
\hline 松科 & Pinaceae & 兴凯赤松 & Pinus densiflora var. ussuriensis & $\mathrm{VU}$ \\
\hline 松科 & Pinaceae & 彰武赤松 & Pinus densiflora var. zhangwuensis & DD \\
\hline 松科 & Pinaceae & 大别五针松 & Pinus fenzeliana var. dabeshanensis & $\mathrm{VU}$ \\
\hline 松科 & Pinaceae & 海南五针松 & Pinus fenzeliana var. fenzeliana & LC \\
\hline 松科 & Pinaceae & 西藏白皮松 & Pinus gerardiana & $\mathrm{CR}$ \\
\hline 松科 & Pinaceae & 卡西亚松 & Pinus kesiya & VU \\
\hline
\end{tabular}


杨永 (2021) 中国裸子植物红色名录评估(2021 版). 生物多样性, 29, 1599-1606. https://www.biodiversityscience.net/CN/10.17520/biods.2021342

\begin{tabular}{|c|c|c|c|c|}
\hline $\begin{array}{l}\text { 中文科名 } \\
\text { Family name_CN }\end{array}$ & $\begin{array}{l}\text { 拉丁科名 } \\
\text { Family name_Latin }\end{array}$ & $\begin{array}{l}\text { 中文种名 } \\
\text { Species name_CN }\end{array}$ & $\begin{array}{l}\text { 拉丁种名 } \\
\text { Species name_Latin }\end{array}$ & $\begin{array}{l}\text { 濒危等级 } \\
\text { Endangered category }\end{array}$ \\
\hline 松科 & Pinaceae & 红松 & Pinus koraiensis & VU \\
\hline 松科 & Pinaceae & 华南五针松 & Pinus kwangtungensis var. kwangtungensis & NT \\
\hline 松科 & Pinaceae & 变叶华南五针松 & Pinus kwangtungensis var. varifolia & DD \\
\hline 松科 & Pinaceae & 南亚松 & Pinus latteri & VU \\
\hline 松科 & Pinaceae & 雅加松 & Pinus massoniana var. hainanensis & VU \\
\hline 松科 & Pinaceae & 马尾松 & Pinus massoniana var. massoniana & VU \\
\hline 松科 & Pinaceae & 沙黄松 & Pinus massoniana var. shaxianensis & DD \\
\hline 松科 & Pinaceae & 台湾五针松 & Pinus morrisonicola & VU \\
\hline 松科 & Pinaceae & 偃松 & Pinus pumila & VU \\
\hline 松科 & Pinaceae & 西藏长叶松 & Pinus roxburghii & $\mathrm{CR}$ \\
\hline 松科 & Pinaceae & 新疆五针松 & Pinus sibirica & VU \\
\hline 松科 & Pinaceae & 巧家五针松 & Pinus squamata & $\mathrm{CR}$ \\
\hline 松科 & Pinaceae & 樟子松 & Pinus sylvestris var. mongolica & VU \\
\hline 松科 & Pinaceae & 长白松 & Pinus sylvestris var. sylvestriformis & EN \\
\hline 松科 & Pinaceae & 欧洲赤松 & Pinus sylvestris var. sylvestris & $\mathrm{LC}$ \\
\hline 松科 & Pinaceae & 巴山松 & Pinus tabuliformis var. henryi & $\mathrm{VU}$ \\
\hline 松科 & Pinaceae & 黑皮油松 & Pinus tabuliformis var. mukdensis & DD \\
\hline 松科 & Pinaceae & 油松 & Pinus tabuliformis var. tabuliformis & $\mathrm{LC}$ \\
\hline 松科 & Pinaceae & 扫帚油松 & Pinus tabuliformis var. umbraculifera & $\mathrm{DD}$ \\
\hline 松科 & Pinaceae & 黄山松 & Pinus taiwanensis & $\mathrm{LC}$ \\
\hline 松科 & Pinaceae & 乔松 & Pinus wallichiana & $\mathrm{LC}$ \\
\hline 松科 & Pinaceae & 毛枝五针松 & Pinus wangii & EN \\
\hline 松科 & Pinaceae & 地盘松 & Pinus yunnanensis var. pygmaea & $\mathrm{LC}$ \\
\hline 松科 & Pinaceae & 云南松 & Pinus yunnanensis var. yunnanensis & LC \\
\hline 松科 & Pinaceae & 金钱松 & Pseudolarix amabilis & VU \\
\hline 松科 & Pinaceae & 短叶黄杉 & Pseudotsuga brevifolia & VU \\
\hline 松科 & Pinaceae & 澜沧黄杉 & Pseudotsuga forrestii & $\mathrm{VU}$ \\
\hline 松科 & Pinaceae & 黄杉 & Pseudotsuga sinensis var. sinensis & $\mathrm{LC}$ \\
\hline 松科 & Pinaceae & 台湾黄杉 & Pseudotsuga sinensis var. wilsoniana & EN \\
\hline 松科 & Pinaceae & 铁杉 & Tsuga chinensis var. chinensis & LC \\
\hline 松科 & Pinaceae & 台湾铁杉 & Tsuga chinensis var. formosana & $\mathrm{VU}$ \\
\hline 松科 & Pinaceae & 丽江铁杉 & Tsuga chinensis var. forrestii & $\mathrm{VU}$ \\
\hline 松科 & Pinaceae & 大果铁杉 & Tsuga chinensis var. robusta & $\mathrm{LC}$ \\
\hline 松科 & Pinaceae & 云南铁杉 & Tsuga dumosa & LC \\
\hline 松科 & Pinaceae & 矩鳞铁杉 & Tsuga oblongisquamata & $\mathrm{LC}$ \\
\hline 罗汉松科 & Podocarpaceae & 鸡毛松 & Dacrycarpus imbricatus & $\mathrm{VU}$ \\
\hline 罗汉松科 & Podocarpaceae & 陆均松 & Dacrydium pectinatum & EN \\
\hline 罗汉松科 & Podocarpaceae & 长叶竹柏 & Nageia fleuryi & $\mathrm{VU}$ \\
\hline 罗汉松科 & Podocarpaceae & 竹柏 & Nageia nagi & EN \\
\hline
\end{tabular}


杨永 (2021) 中国裸子植物红色名录评估(2021 版). 生物多样性, 29, 1599-1606. https://www.biodiversityscience.net/CN/10.17520/biods.2021342

\begin{tabular}{|c|c|c|c|c|}
\hline $\begin{array}{l}\text { 中文科名 } \\
\text { Family name_CN }\end{array}$ & $\begin{array}{l}\text { 拉丁科名 } \\
\text { Family name_Latin }\end{array}$ & $\begin{array}{l}\text { 中文种名 } \\
\text { Species name_CN }\end{array}$ & $\begin{array}{l}\text { 拉丁种名 } \\
\text { Species name_Latin }\end{array}$ & $\begin{array}{l}\text { 濒危等级 } \\
\text { Endangered category }\end{array}$ \\
\hline 罗汉松科 & Podocarpaceae & 肉托竹柏 & Nageia wallichiana & NT \\
\hline 罗汉松科 & Podocarpaceae & 海南罗汉松 & Podocarpus annamiensis & EN \\
\hline 罗汉松科 & Podocarpaceae & 柱冠罗汉松 & Podocarpus chingianus & DD \\
\hline 罗汉松科 & Podocarpaceae & 兰屿罗汉松 & Podocarpus costalis & $\mathrm{CR}$ \\
\hline 罗汉松科 & Podocarpaceae & 簇花罗汉松 & Podocarpus fasciculus & VU \\
\hline 罗汉松科 & Podocarpaceae & 大理罗汉松 & Podocarpus forrestii & $\mathrm{CR}$ \\
\hline 罗汉松科 & Podocarpaceae & 虎克罗汉松 & Podocarpus hookeri & $\mathrm{DD}$ \\
\hline 罗汉松科 & Podocarpaceae & 罗汉松 & Podocarpus macrophyllus var. macrophyllus & VU \\
\hline 罗汉松科 & Podocarpaceae & 毛枝罗汉松 & Podocarpus macrophyllus var. piliramulus & VU \\
\hline 罗汉松科 & Podocarpaceae & 台湾罗汉松 & Podocarpus nakaii & $\mathrm{EN}$ \\
\hline 罗汉松科 & Podocarpaceae & 百日青 & Podocarpus neriifolius & VU \\
\hline 罗汉松科 & Podocarpaceae & 皮氏罗汉松 & Podocarpus pilgeri & $\mathrm{LC}$ \\
\hline 罗汉松科 & Podocarpaceae & 鲁菲斯罗汉松 & Podocarpus rumphii & DD \\
\hline 罗汉松科 & Podocarpaceae & 亚热带罗汉松 & Podocarpus subtropicalis & $\mathrm{DD}$ \\
\hline 罗汉松科 & Podocarpaceae & 小叶罗汉松 & Podocarpus wangii & $\mathrm{EN}$ \\
\hline 红豆杉科 & Taxaceae & 穗花杉 & Amentotaxus argotaenia var. argotaenia & $\mathrm{LC}$ \\
\hline 红豆杉科 & Taxaceae & 短叶穗花杉 & Amentotaxus argotaenia var. brevifolia & $\mathrm{CR}$ \\
\hline 红豆杉科 & Taxaceae & 西藏穗花杉 & Amentotaxus assamica & EN \\
\hline 红豆杉科 & Taxaceae & 台湾穗花杉 & Amentotaxus formosana & $\mathrm{EN}$ \\
\hline 红豆杉科 & Taxaceae & 河口穗花杉 & Amentotaxus hekouensis & $\mathrm{EN}$ \\
\hline 红豆杉科 & Taxaceae & 云南穗花杉 & Amentotaxus yunnanensis & VU \\
\hline 三尖杉科 & Taxaceae & 高山三尖杉 & Cephalotaxus fortunei var. alpina & $\mathrm{LC}$ \\
\hline 三尖杉科 & Taxaceae & 三尖杉 & Cephalotaxus fortunei var. fortunei & $\mathrm{LC}$ \\
\hline 三尖杉科 & Taxaceae & 贡山三尖杉 & Cephalotaxus lanceolata & $\mathrm{CR}$ \\
\hline 三尖杉科 & Taxaceae & 宽叶粗榧 & Cephalotaxus latifolia & $\mathrm{CR}$ \\
\hline 三尖杉科 & Taxaceae & 西双版纳粗榧 & Cephalotaxus mannii & $\mathrm{EN}$ \\
\hline 三尖杉科 & Taxaceae & 篦子三尖杉 & Cephalotaxus oliveri & $\mathrm{VU}$ \\
\hline 三尖杉科 & Taxaceae & 粗榧 & Cephalotaxus sinensis var. sinensis & NT \\
\hline 三尖杉科 & Taxaceae & 台湾粗榧 & Cephalotaxus sinensis var. wilsoniana & $\mathrm{VU}$ \\
\hline 红豆杉科 & Taxaceae & 白豆杉 & Pseudotaxus chienii & $\mathrm{VU}$ \\
\hline 红豆杉科 & Taxaceae & 灰岩红豆杉 & Taxus calcicola & EN \\
\hline 红豆杉科 & Taxaceae & 红豆杉 & Taxus chinensis & VU \\
\hline 红豆杉科 & Taxaceae & 密叶红豆杉 & Taxus contorta & EN \\
\hline 红豆杉科 & Taxaceae & 东北红豆杉 & Taxus cuspidata & $\mathrm{EN}$ \\
\hline 红豆杉科 & Taxaceae & 佛洛琳红豆杉 & Taxus florinii & EN \\
\hline 红豆杉科 & Taxaceae & 南方红豆杉 & Taxus mairei & $\mathrm{VU}$ \\
\hline 红豆杉科 & Taxaceae & 须弥红豆杉 & Taxus wallichiana & EN \\
\hline 红豆杉科 & Taxaceae & 巴山榧树 & Torreya fargesii var. fargesii & VU \\
\hline 红豆杉科 & Taxaceae & 云南木榧 & Torreya fargesii var. yunnanensis & EN \\
\hline
\end{tabular}


杨永 (2021) 中国裸子植物红色名录评估(2021 版). 生物多样性, 29, 1599-1606. https://www.biodiversityscience.net/CN/10.17520/biods.2021342

\begin{tabular}{|c|c|c|c|c|}
\hline $\begin{array}{l}\text { 中文科名 } \\
\text { Family name_CN }\end{array}$ & $\begin{array}{l}\text { 拉丁科名 } \\
\text { Family name_Latin }\end{array}$ & $\begin{array}{l}\text { 中文种名 } \\
\text { Species name_CN }\end{array}$ & $\begin{array}{l}\text { 拉丁种名 } \\
\text { Species name_Latin }\end{array}$ & $\begin{array}{l}\text { 濒危等级 } \\
\text { Endangered category }\end{array}$ \\
\hline 红豆杉科 & Taxaceae & 榧树 & Torreya grandis var. grandis & $\mathrm{LC}$ \\
\hline 红豆杉科 & Taxaceae & 九龙山榧树 & Torreya grandis var. jiulongshanensis & $\mathrm{CR}$ \\
\hline 红豆杉科 & Taxaceae & 长叶榧树 & Torreya jackii & VU \\
\hline
\end{tabular}

